\title{
Условия адсорбционной иммобилизации папаина на сверхсшитых ионообменниках
}

\author{
Шкутина И.В. ${ }^{1}$, Мироненко Н.В. ${ }^{2}$, Саркисян 3.М. ${ }^{1}$, Селеменев В.Ф. ${ }^{2}$ \\ ${ }^{I}$ ФББОУ ВО «Санкт-Петербургский государственный педиатрический медииинский университет», \\ Санкт-Петербург \\ ${ }^{2}$ ФГБОУ ВО «Воронежский государственный университет», Воронеж
}

Поступила в редакцию 3.06.2019 г.

DOI: https://doi.org/10.17308/sorpchrom.2019.19/778

Рассмотрены условия адсорбционной иммобилизации протеолитического фермента папаина на сверхсшитых полимерах A-100 и MN-500. Исследована сорбция папаина в зависимости от времени достижения равновесия, концентрации ионов водорода в растворе. Рассчитаны значения эффективных коэффициентов диффузии. Определены равновесные параметры сорбции с применением адсорбционной теории БЭТ: предельное количество сорбированного папаина, константы, характеризующие взаимодействия типа сорбат-сорбент и сорбат-сорбат.

Ключевые слова: иммобилизация, папаин, сверхсшитые полимеры, каталитическая активность.

\section{The conditions of adsorption immobilization of papain on super-crosslinked ion-exchangers}

\author{
Shkutina I.V. ${ }^{1}$, Mironenko N.V. ${ }^{2}$, Sarkisyan Z.M. ${ }^{1}$, Selemenev V.F. ${ }^{2}$ \\ ${ }^{I}$ FGBOU VO St. Petersburg State Pediatric Medical University, St. Petersburg \\ ${ }^{2}$ FGBOU VO Voronezh State University, Voronezh
}

The regularities of adsorption immobilization of the proteolytic enzyme papain on super-crosslinked polymers A-100 and MN-500 are considered. Super-crosslinked polystyrol has a high specific surface area, characterized by a developed porous structure and significant mobility of the polymer grid, being a matrix for the formation of various nanoclusters of inorganic and organic nature. At the same time, the sorption capacity of these polymers is much higher than the capacity of other types of organic sorbents. One of the advantages of sorbents is also non-toxicity and hemocompatibility

The sorption of papain depending on the time of achieving equilibrium and the concentration of hydrogen ions in the solution were studied. Optimal conditions of adsorption immobilization were established: immobilization time -2 hours, $\mathrm{pH}-6.5$ units, sorbat concentration $-4 \div 5 \cdot 10-2 \mathrm{mmol} / \mathrm{dm}^{3}$.

The obtained experimental kinetic curves indicate that the sorption process is limited by the stage of internal diffusion. The values of effective diffusion coefficients for papain immobilized on MN-500 (7.35 . $\left.10-9 \mathrm{~cm}^{2} / \mathrm{s}\right)$ and A-100 $\left(1.18 \cdot 10-9 \mathrm{~cm}^{2} / \mathrm{s}\right)$ were calculated. It is shown that the best protein sorption is observed at $\mathrm{pH}$ 6.2-6.5 in the region where the catalytic activity of enzyme preparations also had the greatest value. A multi-molecular nature of the received isotherms of papain adsorption on the sorbents was identified. It is noted that during the immobilization of papain on super-crosslinked sorbents the main contribution is made by hydrophobic interactions leading to the manifestation of $\pi-\pi$ - electron interaction between the sorbat and the sorbent. The adsorption isotherms of papain were analyzed using the adsorption theory of BET and the equilibrium parameters of sorption were calculated: the limit amount of sorbed papain, constants characterizing the interaction of the sorbat-sorbent and sorbat-sorbat. 
It is noted that for papain immobilized on $\mathrm{MN}-500$, the sorption equilibrium constant $\left(\mathrm{K}_{\mathrm{L}}=3.58\right.$ $\left.\mathrm{dm}^{3} / \mathrm{mmol}\right)$ is higher than for papain immobilized on A-100 $\left(\mathrm{K}_{\mathrm{L}}=2.17 \mathrm{dm}^{3} / \mathrm{mmol}\right)$. The activity of the heterogeneous biocatalyst papain - MN-500 is $88 \%$ of the activity of the free enzyme. The obtained data indicate the feasibility of further study of the obtained heterogeneous biocatalyst papain - MN-500.

Keywords: immobilization, papain, super-crosslinked polymers, catalytic activity.

\section{Введение}

Папаин (КФ 3.4.22.2) - протеолитический фермент, катализирующий гидролиз белков, пептидов, амидов и сложных эфиров основных аминокислот. Папаин находит применение в пищевой и легкой промышленности. Основное предназначение папаина - использование в медицинских целях. Препараты папаина имеют широкий спектр действия: противовоспалительное, антиоксидантное, иммуностимулирующее, гипотензивное и др. Обладая регенерирующим и ранозаживляющим действием, папаин входит в состав лекарственных форм, применяемых для лечения гнойных осложнений и повреждений кожи различного характера [1].

Все большее применение в промышленности и медицине находят иммобилизованные ферментные системы. Иммобилизация молекул ферментов позволяет регулировать оптимумы функционирования препарата (температуру и $\mathrm{pH}$ ), повысить их устойчивость к денатурирующим факторам, длительно использовать одну партию или серию промышленного биокатализатора. Для медицинских целей необходимо также получение препаратов пролонгированного действия благодаря стабилизации и увеличению времени полужизни фермента, решение проблемы диффузии вещества в организме человека, предотвращение автолиза [2].

При иммобилизации ферментов ключевое значение имеет подбор соответствующего носителя и способа иммобилизации. Одной из основных задач гетерогенных процессов является установление характера взаимодействия сорбата и сорбента, влияния природы сорбционного материала на механизм формирования комплексов, их устойчивость и свойства. Адсорбция ферментов на поверхности носителя оказывает меньшую степень влияния на структуру биомакромолекул белка и активность биокатализатора по сравнению с ковалентным связыванием. К перспективным сорбентам в настоящее время относятся сверхсшитые полистиролы. Они обладают высокой удельной поверхностью, отличаются развитой пористой структурой и значительной подвижностью полимерной сетки, являясь матрицей для формирования в ней различных нанокластеров неорганической и органической природы, проявляя при этом значительно более высокую сорбционную емкость, чем другие типы органических сорбентов. Одним из достоинств сорбентов является также нетоксичность и гемосовместимость [3].

Данные свойства обуславливают широкие возможности их практического применения в качестве высокоэффективных сорбентов для выделения и разделения большого числа органических и неорганических соединений, как в научных исследованиях, так и в производственных процессах [4]. Ранее нами была проведена иммобилизация ферментов на сверхсшитых сорбентах на основе стирола и дивинилбензола [5-7]. Целью данной работы является исследование адсорбционной иммобилизации папаина на сверхсшитых полимерах для оценки дальнейшей возможности изучения и применения гетерогенных биокатализаторов.

\section{Эксперимент}

Объектом исследования являлся ферментный препарат папаин («Sigma», США). В работе были использованы анионообменник с третичными аминогруппами A-100 и сульфокатионообменник MN-500 («Purolite», Россия). Данные носители от- 
носятся к группе сверхсшитых полимерных материалов на основе стирола и дивинилбензола с высокоразвитой удельной поверхностью (900-1200 м²/г) и макропористой структурой.

Кинетические опыты проводили в статических условиях при непрерывном перемешивании раствора методом ограниченного объема [8]. Навески воздушносухого сорбента массой 1.0 г помещали в конические колбы с притертой пробкой объемом $1000 \mathrm{~cm}^{3}$ и заливали раствором папаина с концентрацией $3.2 \cdot 10^{-2}$ ммоль/дм ${ }^{3}$. Через определенные промежутки времени отбирали пробы растворов по $1.0 \mathrm{~cm}^{3}$. Концентрацию белка определяли спектрофотометрически («Shimadzu UV-1800») по методу Лоури, в иммобилизованных препаратах - по модифицированному методу Лоури [9]. Процесс считался завершенным, если с течением времени содержание белка в растворе не изменялось. Растворы папаина готовили на основе $0.2 \mathrm{M}$ ацетатного буфера (pH 4.0-5.0), $0.1 \mathrm{M}$ фосфатного буфера (5.0-8.0) и 0.1 М трисбуфера (8.0-9.0).

Для получения изотерм сорбции использовали метод переменных концентраций. Навески сорбента $(1.0000 \pm 0.0002$ г) приводили в контакт с растворами папаина (pH 6.5) с концентрациями 0.2-5.0 $10^{-2}$ ммоль/дм ${ }^{3}$. Время достижения равновесия было установлено в предварительных кинетических опытах. Опыты проводили в термостатических условиях при $20^{\circ} \mathrm{C}$. Количество белка в фазе сорбента вычисляли по разности концентраций исходного и равновесного растворов. Стандартное отклонение полученных результатов не превышало величину 0.05 . Протеолитическую активность папаина устанавливали по методу Кунитца [10].

\section{Обсуждение результатов}

Определение кинетических закономерностей необходимо для моделирования и расчета параметров отдельных стадий технологических процессов. Полученные в ходе эксперимента кинетические зависимости иммобилизации фермента имеют вид, типичный для процессов адсорбции из растворов, происходящих на пористых поверхностях. Адсорбционный процесс является двухстадийным, при этом первая стадия протекает с высокой скоростью, а на второй стадии процесс замедляется, и скорость его становится близка к нулю. Равновесное значение величины адсорбции папаина достигается в течение 100 мин для MN-500 и 120 мин для A-100 (рис. 1).

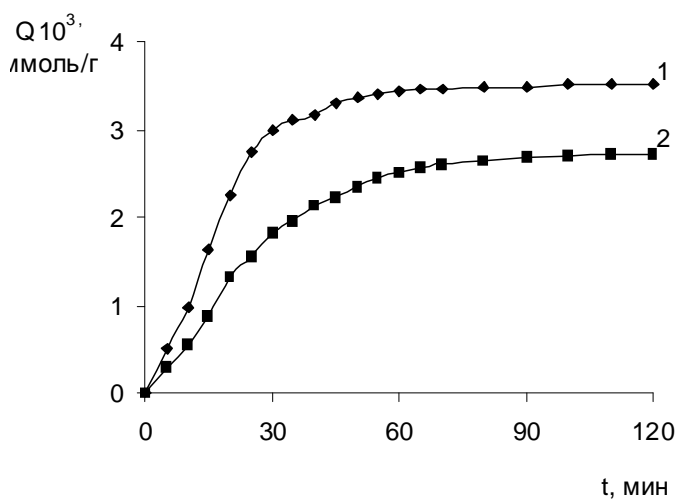

Рис. 1. Кинетические кривые сорбции папаина на MN-500 (1) и A-100 (2): $Q$ - количество сорбированного папаина, ммоль/г; $t-$ продолжительность процесса, мин.

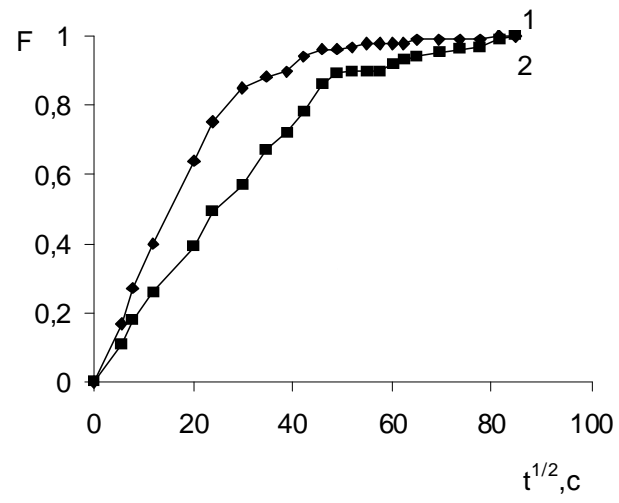

Рис. 2. Зависимость степени заполнения $F$ (усл.ед.) от $t^{1 / 2}$ (с) при сорбции папаина на MN-500 (1) и A-100 (2). 
Проведение предварительной оценки стадии лимитирования возможно только на начальных этапах процесса, учитывая сложный характер сорбции и изменение внешних условий. На кинетический процесс оказывают влияние целый ряд факторов. Среди них - тип адсорбента, степень его сшитости, пористость, набухаемость, температура, реакция среды и т.д. [11]. В процессе иммобилизации следует также учитывать и размеры сорбата, в частности, молекулярная масса папаина составляет 23400 Да.

Линейный характер кривой зависимости степени завершенности процесса $F$ от $t^{1 / 2}$, который наблюдается на начальном участке, свидетельствует о возможном лимитировании процесса сорбции стадией внутренней диффузии (рис. 2).

При вычислении эффективного коэффициента диффузии использовали метод моментов [12]. Среднее время сорбции $\left(t_{c p .}\right)$ вычисляли методом графического интегрирования значения $t$, численно равного площади, ограниченной кинетической кривой, построенной в координатах $F$ - $t$.

$$
\bar{t}_{c p}=\int_{0}^{\infty} t\left(\frac{d F}{d t}\right) d t=\int_{0}^{\infty} t d F
$$

где $\mathrm{F}$ - степень достижения равновесия за время $\mathrm{t}$.

$$
\bar{t}_{c p .}=\frac{r^{2}}{15 \bar{D}},
$$

где $r$ - радиус зерна сорбента в набухшем состоянии (мкм), $\bar{D}-$ эффективный коэффициент диффузии ( $\left.\mathrm{cm}^{2} / \mathrm{c}\right)$.

Полученные экспериментальные данные свидетельствуют о том, что лучшими кинетическими характеристиками обладает MN-500. Так, значение коэффициента диффузии папаина на сорбенте MN-500 оказалось больше, а среднее значение времени сорбции меньше, чем на носителе А-100 (табл.1). Результаты исследований показали, что эффективные коэффициенты внутренней диффузии для папаина согласуются со значениями коэффициентов диффузии, полученных при адсорбции другого фермента - $\alpha$-амилазы (25 000 Да) на сверхсшитом носителе [13].

Таблица 1. Кинетические параметры сорбции папаина

\begin{tabular}{|c|c|c|}
\hline \multirow{2}{*}{ Сорбент } & $\begin{array}{c}\text { Среднее время сорбции, } \\
-\end{array}$ & $\begin{array}{c}\text { Коэффициент диффузии, } \\
t_{c p .} \cdot 10^{2}, c\end{array}$ \\
\hline A-100 & 17.74 & $D, \mathrm{~cm}^{2} / \mathrm{c}$ \\
\hline MN-500 & 11.55 & $1.18 \cdot 10^{-9}$ \\
\hline
\end{tabular}

Другим немаловажным фактором, оказывающим влияние на процесс иммобилизации, является рН среды. Папаин - полипептид, состоящий из 212 аминокислотных остатков, которые в зависимости от кислотности среды могут находиться в виде различных ионных форм, при этом $\mathrm{pI}=8.75$. Активный центр фермента включает аминокислоты цистеин и гистидин. Оптимум действия исследуемого нативного препарата фермента лежит в области рН 6.2-7.0.

Как показали опыты, наибольшее количество белка связывается с носителями при рН 6.2-6.5 (рис. 3), при данном значении иммобилизованный фермент проявляет и наибольшую каталитическую активность. Активность папаина, иммобилизованного на MN-500, составляет 89\% (2225 Ед/мг), для А-100 - 67\% (1675 Ед/мг) от активности нативного энзима. Хотя при иммобилизации активность ферментов снижается, однако интегральная активность, определяемая суммарным количеством полученного продукта, будет выше. Связывание фермента не приводит к изменению рН опти- 
мума фермента, т.е. можно предположить, что не затрагиваются функциональные группы активного центра.

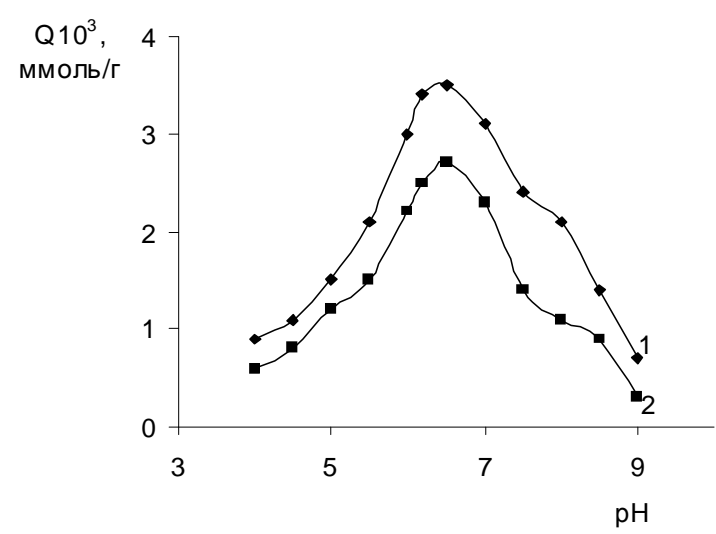

Рис. 3. Зависимость количества сорбированного папаина $(\mathrm{Q}$, ммоль/г) на MN-500 (1) и A-100 (2) от $\mathrm{pH}$ равновесного раствора

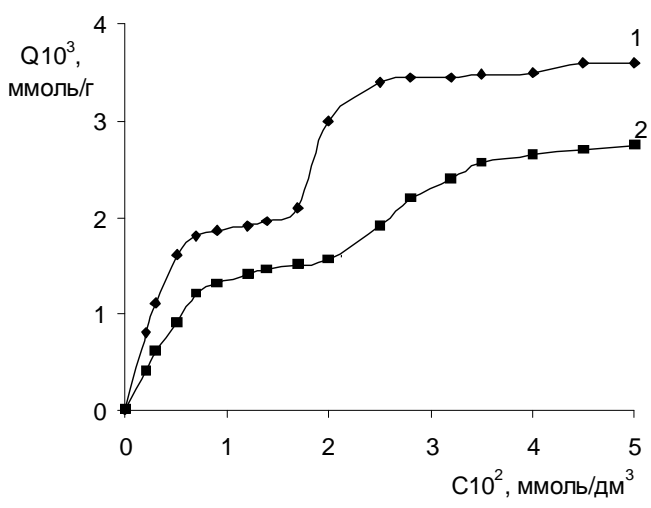

Рис. 4. Изотермы сорбции папаина на MN-500 (1) и A-100 (2) при рН 6.5:

$\mathrm{C}$ - равновесная концентрация белка в растворе, ммоль/дм³.

Изотермы сорбции папаина на сверхсшитых носителях, полученные при $\mathrm{pH}$ 6.5, представлены на рис. 4. S-образный вид изотерм предполагает изменение механизма сорбционного закрепления белка с ростом его концентрации в равновесном растворе. Линейная зависимость и образование практически горизонтального участка на изотерме в области малых концентраций раствора соответствуют формированию мономолекулярного слоя сорбата.

После завершения образования мономолекулярного слоя, при концентрации папаина в растворе выше $2 \cdot 10^{-2}$ ммоль/дм ${ }^{3}$, сорбция приобретает полимолекулярный характер, что проявляется на изотермах резким увеличением количества сорбированного папаина. Определяющую роль при иммобилизации папаина на сверхсшитых полимерах играют, вероятно, гидрофобные взаимодействия, ведущие к образованию супрамолекулярных комплексов. Кроме того, на носителе MN-500, содержащем сульфогруппы, незначительная доля фермента может сорбироваться за счет ионного обмена, так как при $\mathrm{pH} 6.5$ большая часть белка находится в форме катиона.

В большинстве случаев мономолекулярный адсорбционный слой не компенсирует полностью избыточную поверхностную энергию, и влияние поверхностных сил может распространяться на второй, третий и последующие адсорбционные слои с образованием на поверхности адсорбента «последовательных комплексов» адсорбционных центров с одной, двумя, тремя и т. д. молекулами сорбата. Для количественного описания изотерм сорбции папаина сверхсшитыми сорбентами была применена модель БЭТ [14].

Количество иммобилизованного фермента находили по формуле:

$$
Q=\frac{Q_{\infty} K_{L} c_{p}}{\left(1-K_{\mathrm{S}} c_{p}\right)\left(1-K_{S} C_{p}+K_{L} c_{p}\right)},
$$

где $\mathrm{Q} \cdot 10^{-3} \cdot$ - количество сорбируемого белка, ммоль/г; $\mathrm{Q}_{\infty} \cdot 10^{-3}$ - предельное количество сорбированного белка (емкость - количество сорбируемого белка монослоя), ммоль/г; $\mathrm{c}_{\mathrm{p}} \cdot 10^{-2}$ - равновесная концентрация раствора, ммоль/дм ${ }^{3} ; \mathrm{K}_{\mathrm{L}}-$ константа сорбционного равновесия, характеризующая интенсивность процесса сорбции, дм $^{3} /$ ммоль; $\mathrm{K}_{\mathrm{S}}$ - константа сорбционного равновесия для полимолекулярного слоя, дм $\mathbf{m}^{3} /$ ммоль. 
Величины констант сорбционного равновесия, входящих в уравнение изотермы БЭТ, рассчитывали, используя линеаризованное уравнение:

$$
\frac{c_{p}}{Q\left(1-K_{S} c_{p}\right)}=\left(\frac{K_{L}-K_{S}}{Q_{\infty} K_{L}}\right) c_{p}+\frac{1}{Q_{\infty} K_{L}} .
$$

Предельное количество иммобилизованного фермента, входящего в мономолекулярный слой, определяли из уравнений $(5,6)$ :

$$
\begin{aligned}
Q_{\infty} & =\frac{1}{b \cdot K_{L}}, \\
K_{L} & =\frac{k}{b}+K_{S} .
\end{aligned}
$$

Константу сорбционного равновесия для полимолекулярного слоя $\left(\mathrm{K}_{\mathrm{s}}\right)$ определяли из максимальной величины достоверности аппроксимации прямой $\left(c_{p}-c_{p} / \mathrm{Q}\left(1-\mathrm{K}_{\mathrm{S}} c_{p}\right)\right)$.

Таблица 2. Значения сорбционных параметров, рассчитанных с использованием уравнений БЭТ

\begin{tabular}{|c|c|c|c|c|}
\hline Сорбент & $\begin{array}{c}K_{\mathrm{L}}, \\
\text { дм }^{3} / \text { ммоль }\end{array}$ & $\begin{array}{c}Q_{\infty} \cdot 10^{-3}, \\
\text { ммоль } / \Gamma\end{array}$ & $\begin{array}{c}K_{\mathrm{S}}, \\
\text { дм }^{3} / \text { ммоль }\end{array}$ & $R^{2}$ \\
\hline $\mathrm{A}-100$ & 2.17 & 1.36 & 0.19 & 0.96 \\
\hline $\mathrm{MN}-500$ & 3.58 & 1.98 & 0.40 & 0.97 \\
\hline
\end{tabular}

Рассчитанные значения сорбционных параметров представлены в табл.2. Для папаина, иммобилизованного на $\mathrm{MN}-500$, константа сорбционного равновесия $\left(\mathrm{K}_{\mathrm{L}}=3.58\right.$ дм³ $^{3}$ ммоль) оказалась выше, чем для папаина, иммобилизованного на А-100 $\left(\mathrm{K}_{\mathrm{L}}=2.17\right.$ дм $^{3} /$ ммоль), что следует и из экспериментальных изотерм сорбции фермента. Также можно отметить, что полученные значения констант сопоставимы с величинами констант $\mathrm{K}_{\mathrm{L}}$ и $\mathrm{K}_{\mathrm{S}}$ для органических веществ, имеющих значительную молекулярную массу, при сорбции пористыми сорбентами $[15,16]$.

\section{Заключение}

Исследована сорбционная способность сверхсшитых полимерных ионообменников A-100 и MN-500 по отношению к протеолитическому ферменту папаин. Установлены оптимальные условия адсорбционной иммобилизации: время иммобилизации -2 часа, $\mathrm{pH}-6.5$ ед., концентрация сорбата $-4-5 \cdot 10^{-2}$ ммоль/дм ${ }^{3}$. При этом активность гетерогенных биокатализаторов составляет 67-89\% от активности нативного фермента.

Вычислены значения эффективных коэффициентов диффузии при иммобилизации папаина на MN-500 и A-100. Показано, что изотермы сорбции папаина на сверхсшитых сорбентах имеют полимолекулярный характер. Рассчитаны значения сорбционных параметров с использованием уравнений БЭТ.

Выявлены возможность и условия получения гетерогенных биокатализаторов папаин - A-100 и папаин - MN-500.

\section{Список литературы}

1. Бунятян Н.Д., Заинкова Н.В., Муравьева Т.И. и др. // Фундаментальные исследования. 2015. № 2. C. 514-517.
2. Биотехнология / Ю.О. Сазыкин, С.Н. Орехов, И.И. Чакалева; под ред. А.В. Катлинского. М. Академия. 2008. 256 с. 
3. Tsyurupa M.P., Davankov V.A. // React. Funct. Polym. 2002. Vol. 53. pp. 193-203.

4. Филиппов О.А., Тихомирова Т.И., Цизин Г.И., Золотов Ю.А. // Журнал аналитической химии. 2003. Т.58. № 5. С. 454-479.

5. Селеменев В.Ф., Стоянова О.Ф., Шкутина И.В. Патент РФ. №2181770. 2002.

6. Шкутина И.В., Стоянова О.Ф., Селеменев В.Ф. // Журнал прикладной химии. 2001. Т. 74. № 5. C.869-871.

7. Shkutina I.V., Stoyanova O.F., Selemenev V.F. // Russ. J. of Bioorganic Chemistry. 2016. Vol. 42. No 7. pp. 64-67.

8. Селеменев В.Ф., Славинская, В.Ю., Хохлов В.Ю. и др. Практикум по ионному обмену. Воронеж. Изд-во ВГУ. 2004. 160 с.

9. Chibata I. // Pure and Appl.Chem. 1978. Vol. 50. No 7. pp. 667-675.

10. Kunitz M. // J. Gen Physiol. 1947. No 30. pp. 291-310.

\section{References}

1. Bunyatyan N.D., Zainkova N.V., Murav'eva T.I. et al., Fundamental'nye issledovaniya, 2015, No 2, pp. 514-517.

2. Biotekhnologiy, Yu.O. Sazykin, S.N. Orekhov, I.I. CHakaleva; pod red. A.V. Katlinskogo. M. Akademiya. 2008. 256 p.

3. Tsyurupa M.P., Davankov V.A., React. Funct. Polym., 2002, Vol. 53, pp. 193-203.

4. Filippov O.A., Tikhomirova T.I., TSizin G.I., Zolotov Yu.A., ZHurnal analiticheskoj khimii, 2003, Vol. 58, No 5, pp. 454-479.

5. Selemenev V.F., Stoyanova O.F., SHkutina I.V. Patent RF. №2181770. 2002.

6. SHkutina I.V., Stoyanova O.F., Selemenev V.F., ZHurnal prikladnoj khimii, 2001, Vol. 74, No 5, pp. 869-871.

7. Shkutina I.V., Stoyanova O.F., Selemenev V.F., Russ. J. of Bioorganic Chemistry, 2016, Vol. 42, No 7, pp. 64-67.

8. Celemenev V.F., Slavinskaya, V.Yu., KHokhlov V.YU. et al, Praktikum po ionnomu obmenu. Voronezh, Izd-vo VGU, 2004, 160 p.

Шкутина Ирина Викторовна - к.б.н., доцент кафедры общей и медицинской химии им. проф. В.В. Хорунжего, Санкт-Петербургский государственный педиатрический медицинский университет, Санкт-Петербург

Мироненко Наталья Владимировна - к.Х.н., ассистент кафедры аналитической химии, Воронежский государственный университет, Воронеж
11. Знаменский Ю.П., Бычков Н.В. Кинетика ионообменных процессов. Обнинск. Принтер. 2000. 204 с.

12. Кокотов Ю.А., Пасечник В.А. Равновесие и кинетика ионного обмена. Л. Химия. $1970.336 \mathrm{c.}$

13. Шкутина И.В., Мироненко Н.В., Стоянова О.Ф., Селеменев В.Ф. // Журнал прикладной химии. 2012. Т. 85. № 6. С.10171019.

14. Amanollah E., Jafar S., Soltan M. // Adsorption. 2009. Vol. 15. No 1. pp. 65-73.

15. Мироненко Н.В., Смусева С.О., Брежнева Т.А., Селеменев В.Ф. // Журнал физическойхимии. 2016. Т. 90. № 12. С. 1870-1875.

16. Котова Д.Л., ФамТхи Гам, Крысанова Т.А. и др.// Сорбчиионные и хроматографические прочессы. 2014. Т. 14. № 4. С. 572577.

9. Chibata I., Pure and Appl.Chem., 1978, Vol. 50, No 7, pp. 667-675.

10. Kunitz M., J. Gen Physiol., 1947, No 30, pp. 291-310.

11. Znamenskij Yu.P., Bychkov N.V., Kinetika ionoobmennykh protsessov, Obninsk, Printer, 2000, $204 \mathrm{p}$.

12. Kokotov Yu.A., Pasechnik V.A., Ravnovesie i kinetika ionnogo obmena, L., Khimiya, 1970, 336 p.

13. SHkutina I.V., Mironenko N.V., Stoyanova O.F., Selemenev V.F., ZHurnal prikladnoj khimii, 2012, Vol. 85, No 6, pp. 1017-1019.

14. Amanollah E., Jafar S., Soltan M., Adsorption, 2009, Vol. 15, No 1, pp. 65-73.

15. Mironenko N.V., Smuseva S.O., Brezhneva T.A., Selemenev V.F., ZHurnal fizicheskoj khimii, 2016, Vol. 90, No 12, pp. 1870-1875.

16. Kotova D.L., FamTkhi Gam, Krysanova T.A.et al., Sorbtsionnye i khromatograficheskie protsessy, 2014, Vol. 14, No 4, pp. 572-577.

Shkutina Irina V. - assistant professor of general and medical chemistry department after prof. V.V. Khorunzhii, State Pediatric Medical University, St. Petersburg, e-mail: irn55@mail.ru

Mironenko Nataliya V. - assistant of analytical chemistry department of chemical faculty, Voronezh State University, Voronezh, e-mail: natashamir@yandex.ru 
Саркисян Зара Микаэловна - к.Х.н., доцент, зав. кафедрой общей и медицинской химии им. проф. В.В. Хорунжего, Санкт-Петербургский государственный педиатрический медицинский университет, Санкт-Петербург

Селеменев Владимир Федорович - д.х.н., профессор, зав. кафедрой аналитической химии, Воронежский государственный университет, Воронеж.
Sarkisyan Zara M. - assistant professor, head of Department of general and medical chemistry after prof. V.V. Khorunzhii, State Pediatric Medical University, St. Petersburg, zara-sark@inbox.ru.

Selemenev Vladimir V. - doctor of science, professor, head of Department of analytical chemistry, chemical faculty, Voronezh State University, Voronezh 